\title{
Spurious Thyroid Function Test Results due to Biotin Interference: a Report of Three Cases and a Literature Review
}

\author{
Ji Yong Park, Wonsuk Choi, Jee Hee Yoon and Ho-Cheol Kang \\ Department of Internal Medicine, Chonnam National University Hwasun Hospital, Chonnam National University Medical School, \\ Gwangju, Korea
}

Biotin (vitamin B7) is a water-soluble vitamin used as a co-enzyme for carboxylases essential for human metabolism. The high affinity to streptavidin makes biotin an important substance in immunoassays. Excessive biotin intake due to over-the counter supplements has become problematic because of the effects on laboratory test results. There have been no reports of biotin-induced thyroid immunoassay interference in Korea. We report three patients with papillary thyroid cancer who showed false thyrotoxicosis on follow-up laboratory examinations with a literature review. The patients' medical history should be thoroughly questioned and patients should be informed to curtail consuming biotin before laboratory tests to avoid assay interference. Non-biotinylated assays can be considered if it is impossible to withhold the supplements. These methods will prevent physicians from making incorrect decisions that could result in an inappropriate treatment for their patients.

Key Words: Biotin, Interference, Immunoassay, Thyroid function tests

\section{Introduction}

Biotin (vitamin B7) is a water-soluble vitamin and well known as a coenzyme for multiple bicarbonate-dependent carboxylases essential for human metabolism. ${ }^{1)}$ The Food and Nutrition Board of the National Research Council recommends $30 \mu \mathrm{g} /$ day biotin as adequate intakes for adults. ${ }^{2)}$ Recent studies have shown the benefit of biotin for medical conditions, such as hair and nail problems, diabetes mellitus, ${ }^{3)}$ peripheral neuropathy, ${ }^{4)}$ and multiple sclerosis, ${ }^{5}$ therefore, over-the-counter biotin supplements have become popular.

Because of the high affinity to streptavidin, biotin has a crucial role in immunoassays. ${ }^{6)}$ Excessive biotin intake can affect laboratory test results, and it can mislead physicians resulting in inappropriate treatments for patients. ${ }^{7)}$

There have been no reports in South Korea about biotin-induced interference in thyroid function tests (TFTs). We report three patients with papillary thyroid cancer (PTC) who showed false thyrotoxicosis on follow-up studies with a literature review.

\section{Case Reports}

\section{Case 1}

An 83-year-old female who had a total thyroidectomy for PTC 10 years ago and had been taking $125 \mu \mathrm{g} /$ day levothyroxine underwent follow-up annual

Received December 15, 2020 / Revised 1st January 8, 2021, 2nd January 26, 2021 / Accepted January 28, 2021

Correspondence: Ho-Cheol Kang, MD, PhD, Department of Internal Medicine, Chonnam National University Medical School, 160 Baekseo-ro, Dong-gu, Gwangju 61469, Korea

Tel: 82-61-379-7620, Fax:82-61-379-7628, E-mail: drkang@chonnam.ac.kr 
TFTs. Surprisingly, her serum total triiodothyronine (T3) was $>651 \mathrm{ng} / \mathrm{dl}$ (normal range, 60-160), free thyroxine (FT4) was $2.06 \mathrm{ng} / \mathrm{dl}$ (normal range, 0.81.71), and thyroid stimulating hormone (TSH) was 0.65 $\mu \mathrm{IU} / \mathrm{ml}$ (normal range, 0.4-4.8). The hormones were measured with a chemiluminescent immunoassay (Cobas: Roche Diagnostics, West Sussex, UK). However, she had no symptoms or signs of thyrotoxicosis, including weight change. A subsequent detailed history revealed the culprit. We figured out that the vitamin supplement (Adult multivitamin Gummies, Kirkland Signature, Costco, Seattle, WA, USA) which she had been taking for several months contained $300 \mu \mathrm{g}$ biotin per tablet. Her serum total T3 level normalized to $110 \mathrm{ng} / \mathrm{dl} 1$ week after stopping the supplement (Table 1).

\section{Case 2}

A 43-year-old female who had a left lobectomy for PTC 9 years ago underwent annual follow-up TFTs. Her serum total T3 was $633 \mathrm{ng} / \mathrm{dl}$, free T4 was 2.42 $\mathrm{ng} / \mathrm{dl}$, and TSH was $0.786 \mu \mathrm{lU} / \mathrm{ml}$ without any signs of thyrotoxicosis including weight change. We checked her anti-thyroglobulin antibody on regular basis and the results were always negative. She had neither been on levothyroxine replacement nor showed any features of thyroiditis on thyroid ultrasonography. She had been taking several complex health supplements, including vitamin $\mathrm{C}$, probiotics, and diet products for several months. Although biotin was not identified on the labels of any of the products, we assumed that fruit extracts in the diet products or biotin-producing microbes in the probiotics could affect the biotin level to cause laboratory errors. Repeat TFT results normalized 1 week after stopping all the supplements (Table 1).

\section{Case 3}

A 69-year-old male PTC patient who had a total thyroidectomy 10 years ago and had been taking 125 $\mu \mathrm{g}$ of levothyroxine daily presented with severe thyrotoxicosis without any symptoms of thyrotoxicosis: total T3, $651 \mathrm{ng} / \mathrm{dl}$; free T4, $5.02 \mathrm{ng} / \mathrm{dl}$; and TSH, $0.049 \mu \mathrm{lU} / \mathrm{ml}$. His body weight was constant during the follow up visits. The patient had been taking a supplement containing royal jelly (Royal Jelly, Nature's Family, Sydney, NSW, Australia) for several months. The patient was advised to stop taking the supplement. After 1 week, we confirmed that his TFT results were normal (Table 1). Later, we were informed that royal jelly is the rich source for multiple vitamins including biotin.

\section{Discussion}

The streptavidin-biotin complex has been used in a variety of immunoassays. The analyte concentration and the signal are inversely proportional in competitive assays (e.g., free T4 and total T3). If the biotin concentration is supraphysiological, it competes with the biotinylated analytes and the assay shows a low signal. As a result, free T4 and total T3 will be higher than the true value. In contrast, the signal increases in proportion to the analyte concentration in uncompetitive sandwich assays (e.g., TSH). Excess biotin will compete with the analyte complex and show results that are lower than the true value. ${ }^{8,9)}$ As a consequence, the TSH level will be falsely low.

The patients' drug history must be determined to avoid assay interference, and any suspicious supplements containing biotin should be identified. Although

Table 1. Thyroid function test results

\begin{tabular}{|c|c|c|c|c|c|c|c|}
\hline & \multicolumn{2}{|c|}{ Case 1} & \multicolumn{2}{|c|}{ Case 2} & \multicolumn{2}{|c|}{ Case 3} & \multirow{2}{*}{$\begin{array}{c}\text { Reference } \\
\text { ranges }\end{array}$} \\
\hline & $\begin{array}{c}\text { On } \\
\text { supplement }\end{array}$ & $\begin{array}{c}\text { Off } \\
\text { supplement }\end{array}$ & $\begin{array}{c}\text { On } \\
\text { supplement }\end{array}$ & $\begin{array}{c}\text { Off } \\
\text { supplement }\end{array}$ & $\begin{array}{c}\text { On } \\
\text { supplement }\end{array}$ & $\begin{array}{c}\text { Off } \\
\text { supplement }\end{array}$ & \\
\hline FT4 (ng/dl) & 2.06 & 1.82 & 2.42 & 1.26 & 5.02 & 1.01 & $0.8-1.71$ \\
\hline TT3 (ng/dl) & $>651$ & 110 & 633 & 84 & 651 & 80 & $60-160$ \\
\hline $\mathrm{TSH}(\mu \mathrm{U} / \mathrm{ml})$ & 0.650 & 0.144 & 0.786 & 3.34 & 0.049 & 0.417 & $0.4-4.8$ \\
\hline
\end{tabular}

FT4: free thyroxine, TSH: thyroid stimulating hormone, TT3: total triiodothyronine 
we were not able to identify biotin contents in the health supplements in Case 2, we assumed that fruit extracts in the supplements or biotin-producing microbes in the probiotics product might contribute to the elevation of serum biotin level. ${ }^{10)}$ The relationship between the probiotics and the biotin-utilizing immunoassays needs to be further studied. We considered that the possibility of thyroiditis would be unlikely because her TFT recovered in only 1 week after withdrawing the supplements, her anti-thyroglobulin antibody levels were within normal range during the follow up visits, and T3-dominant thyrotoxicosis did not fit with the typical findings of thyroiditis. ${ }^{11)}$ In Case 3 , later, we were informed that royal jelly is the source for biotin. A study has shown that royal jelly contains 84.3 nmol/g biotin. ${ }^{12)}$ Thus, any supplements that may contain biotin must be discontinued before retesting. The time needed to restrain from using the supplements increases with the biotin dose because biotin level is positively correlated with the strength of interference. ${ }^{13)}$ The American Association for Clinical Chemistry guidelines for biotin interference on laboratory tests recommends at least an 8 hour withdrawal period for patients who take $5-10 \mathrm{mg}$ biotin and 72 hours for higher doses of biotin (>100 mg/day) before blood tests. ${ }^{14)}$ Secondly, if it is impossible to withhold the supplements, non-biotinylated assays are another option. Li et al. ${ }^{14)}$ compared multiple immunoassays with different assay systems related to biotin intake. According to that study, biotinylated assays, such as the Roche Cobas assay, show significantly different total T3, free T4, and free T3 after ingesting biotin. ${ }^{14}$ As clinical laboratories in Chonnam University Hwasun Hospital have used the Roche Cobas assay system for thyroid immunoassays, the test results were concordant with previous case reports that used biotinylated assays (Table 2). ${ }^{8,15-19)}$ Piketty et al. ${ }^{13)}$ suggested effective neutralization methods to suppress biotin interference, which needs further studies to be widely used.

It is difficult to be aware of biotin interference when a PTC patient who is on levothyroxine suppressive therapy consumes a biotin supplement because we commonly suppress TSH levels to prevent the recurrence of thyroid cancer. Excess biotin intake misleads the physician to decide to lower the dose of levothyroxine, which may be suboptimal for the patient.

This report is the first case series of biotin-induced

Table 2. Summary of case reports on biotin-induced thyroid immunoassay interference

\begin{tabular}{|c|c|c|c|c|c|c|c|c|}
\hline Author (year) & $\begin{array}{l}\text { Gender, age, } \\
\text { disease }\end{array}$ & Biotin dose & Assay(s) & TSH & FT4 & FT3/TT3 & TRAb & $\begin{array}{l}\text { LT4 } \\
\text { intake }\end{array}$ \\
\hline $\begin{array}{l}\text { Wijeratne } \\
\text { et al. }{ }^{9}(2012)\end{array}$ & $\begin{array}{l}\text { Male, Healthy } \\
\text { subject }\end{array}$ & 30 mg/day & Beckman Dxl & - & $\uparrow$ & $\uparrow$ & - & No \\
\hline $\begin{array}{l}\text { Elston et al. }{ }^{8)} \\
(2016)\end{array}$ & Female, 63, MS & 100 mg TID & Roche Cobas 6000 & $\downarrow$ & $\uparrow$ & $\uparrow$ & $\uparrow$ & No \\
\hline $\begin{array}{l}\text { Barbesino }^{15)} \\
(2016)\end{array}$ & Male, 55, MS & 100 mg TID & Roche Elecsys & $\downarrow$ & $\uparrow$ & $\uparrow$ & $\uparrow$ & No \\
\hline $\begin{array}{l}\text { Al-Salameh } \\
\text { et al. }^{18)}(2017)\end{array}$ & Male, 32, XAL & 100 mg TID & Roche Cobas e170 & $\downarrow$ & $\uparrow$ & $\uparrow$ & $\uparrow$ & No \\
\hline $\begin{array}{l}\text { Ardabilygazir } \\
\text { et al. }{ }^{19)}(2018)\end{array}$ & $\begin{array}{l}\text { Female, } 49, \mathrm{MS} \\
\text { GD post iodine-131 }\end{array}$ & 200 mg/day & No description & $\downarrow$ & $\uparrow$ & $\uparrow$ & - & Yes \\
\hline $\begin{array}{l}\text { Koehler et al. }{ }^{16)} \\
(2018)\end{array}$ & Male, 47, MS & 100 mg TID & No description & $\downarrow$ & $\uparrow$ & $\uparrow$ & $\uparrow$ & No \\
\hline \multirow{2}{*}{$\begin{array}{l}\text { Odhaib et al. }{ }^{17)} \\
(2019)\end{array}$} & Female, 23 & $20 \mathrm{mg} / \mathrm{day}$ & Roche Cobas e411 & $\downarrow$ & $\uparrow$ & $\uparrow$ & $\uparrow$ & No \\
\hline & Male, 45, NTT & 30 mg/day & Roche Cobas e411 & $\downarrow$ & $\uparrow$ & $\uparrow$ & $\uparrow$ & Yes \\
\hline \multirow[t]{3}{*}{ Park (2021) } & Female, 83, PTC & $300 \mu \mathrm{g} /$ day & Roche Cobas c702 & $\downarrow$ & $\uparrow$ & $\uparrow$ & - & Yes \\
\hline & Female, 43, PTC & - & Roche Cobas c702 & $\downarrow$ & $\uparrow$ & $\uparrow$ & - & No \\
\hline & Male, 69, PTC & - & Roche Cobas c702 & $\downarrow$ & $\uparrow$ & $\uparrow$ & - & Yes \\
\hline
\end{tabular}

FT3: free triiodothyronine, FT4: free thyroxine, GD: Graves' disease, LT4: levothyroxine, MS: multiple sclerosis, NTT: near total thyroidectomy, PTC: papillary thyroid cancer, TID: three times per day, TRAb: thyrotropin receptor antibody, TSH: thyroid stimulating hormone, TT3: total triiodothyronine, TT4: total thyroxine, XAL: X-linked adrenomyeloneuropathy 
thyroid immunoassay interference in South Korea. Biotin interference should be considered when TFT results are discordant with clinical findings because biotin use is widespread, and some health supplements contain concealed biotin. If interference by biotin is suspected, repeating the TFT after withholding the biotin supplement for 1 week is a reasonable approach.

\section{Conflicts of Interest}

No potential conflict of interest relevant to this article was reported.

\section{Orcid}

Ji Yong Park: https://orcid.org/0000-0002-6563-7673

Wonsuk Choi: https://orcid.org/0000-0002-0523-0839 Jee Hee Yoon: https://orcid.org/0000-0002-5919-6162 Ho-Cheol Kang: https://orcid.org/0000-0002-0448-1345

\section{References}

1) Zempleni J, Wijeratne SS, Hassan YI. Biotin. Biofactors 2009;35(1):36-46.

2) Yates AA, Schlicker SA, Suitor CW. Dietary reference intakes: the new basis for recommendations for calcium and related nutrients, B vitamins, and choline. J Am Diet Assoc 1998;98(6): 699-706.

3) Sasaki Y, Sone H, Kamiyama S, Shimizu M, Shirakawa H, Kagawa $\mathrm{Y}$, et al. Administration of biotin prevents the development of insulin resistance in the skeletal muscles of Otsuka Long-Evans Tokushima Fatty rats. Food Funct 2012;3(4):414-9.

4) Koutsikos D, Agroyannis B, Tzanatos-Exarchou H. Biotin for diabetic peripheral neuropathy. Biomed Pharmacother 1990; 44(10):511-4.

5) Tourbah A, Lebrun-Frenay C, Edan G, Clanet M, Papeix C, Vukusic S, et al. MD1003 (high-dose biotin) for the treatment of progressive multiple sclerosis: a randomised, double-blind, placebo-controlled study. Mult Scler 2016;22(13):1719-31.

6) Dundas CM, Demonte D, Park S. Streptavidin-biotin technology: improvements and innovations in chemical and biological applications. Appl Microbiol Biotechnol 2013;97(21):9343-53.

7) Li D, Radulescu A, Shrestha RT, Root M, Karger AB, Killeen $\mathrm{AA}$, et al. Association of biotin ingestion with performance of hormone and nonhormone assays in healthy adults. JAMA 2017; 318(12):1150-60.

8) Elston MS, Sehgal S, Du Toit S, Yarndley T, Conaglen JV. Factitious Graves' disease due to biotin immunoassay interference-a case and review of the literature. J Clin Endocrinol Metab 2016; 101(9):3251-5.

9) Wijeratne NG, Doery JC, Lu ZX. Positive and negative interference in immunoassays following biotin ingestion: a pharmacokinetic study. Pathology 2012;44(7):674-5.

10) Yoshii K, Hosomi K, Sawane K, Kunisawa J. Metabolism of dietary and microbial vitamin $B$ family in the regulation of host immunity. Front Nutr 2019;6:48.

11) Shigemasa $C$, Abe K, Taniguchi S, Mitani Y, Ueda Y, Adachi $\mathrm{T}$, et al. Lower serum free thyroxine (T4) levels in painless thyroiditis compared with Graves' disease despite similar serum total T4 levels. J Clin Endocrinol Metab 1987;65(2):359-63.

12) Hayakawa K, Katsumata N, Hirano M, Yoshikawa K, Ogata $\mathrm{T}$, Tanaka T, et al. Determination of biotin (vitamin H) by the high-performance affinity chromatography with a trypsintreated avidin-bound column. J Chromatogr B Analyt Technol Biomed Life Sci 2008;869(1-2):93-100.

13) Piketty ML, Prie D, Sedel F, Bernard D, Hercend C, Chanson $\mathrm{P}$, et al. High-dose biotin therapy leading to false biochemical endocrine profiles: validation of a simple method to overcome biotin interference. Clin Chem Lab Med 2017;55(6): $817-25$.

14) Li D, Ferguson A, Cervinski MA, Lynch KL, Kyle PB. AACC guidance document on biotin interference in laboratory tests. J Appl Lab Med 2020;5(3):575-87.

15) Barbesino G. Misdiagnosis of Graves' disease with apparent severe hyperthyroidism in a patient taking biotin megadoses. Thyroid 2016;26(6):860-3.

16) Koehler VF, Mann U, Nassour A, Mann WA. Fake news? Biotin interference in thyroid immunoassays. Clin Chim Acta 2018;484:320-2.

17) Odhaib SA, Mansour AA, Haddad NS. How biotin induces misleading results in thyroid bioassays: case series. Cureus 2019;11(5):e4727.

18) Al-Salameh A, Becquemont L, Brailly-Tabard S, Aubourg P, Chanson P. A somewhat bizarre case of Graves disease due to vitamin treatment. J Endocr Soc 2017;1(5):431-5.

19) Ardabilygazir A, Afshariyamchlou S, Mir D, Sachmechi I. Effect of high-dose biotin on thyroid function tests: case report and literature review. Cureus 2018;10(6):e2845. 